\title{
Discussing responsibility and ways of influencing health
}

\author{
By OUTI JOLANKI
}

\begin{abstract}
In this discursive study of four group discussions, I examine how the study participants respond to questions about the possibilities of individuals to influence their own health and their responsibility for health, and what is the role of old age in this context. One key finding was that the participants balanced between seeing health as a do-it-yourself matter and on the other hand as a matter of fate or chance. The participants did not question the idea that they could influence their health or assume responsibility for their own health, but they did raise several factors that limit individual influence. Focus groups proved to be an appropriate data collection method for studying morally laden and potentially sensitive issues. It is suggested that the findings of this small-scale study echo broader western discourses on health and old age and contemporary cultural and social developments.
\end{abstract}

Keywords: health, ageing, old age, responsibility, culture, qualitative study, focus group discussions, discourse. 
International Journal of Ageing and Later Life

\section{Introduction}

Health and information about different health risks and ways to minimise them and enhance one's own well-being are frequent topics in public discourse, in the media and in everyday conversation. As Robert Crawford (2006) has argued, "health may be reasonably described as social cynosure ... both a goal and a source of anxiety, a value for self and others, integral to identity, a state of being that is continually assessed and the organising concept for a vast organisation of social action" (Crawford 2006: 404).

Health also provides a common conceptual framework for views about ageing, old age and the lives of old people (Featherstone \& Hepworth 1995; Katz 2000). Health discourses are not, nor have ever been, unitary or unambiguous. However, a distinctive feature of contemporary thinking about health is that this is a matter that every individual can and should "do something about", by means of their own actions and lifestyle choices. Accordingly, health talk has become talk about individual responsibility (Crawford 2006).

In today's social and cultural climate, which stresses individual effort and responsibility for health, seeing old age as a health issue easily leads to seeing it in terms of individual life choices and decisions. This view challenges the traditional discourse of decline, which has it that ageing is a common fate for all people and inevitably means physical and mental deterioration. Within this discourse, there is little room for individual action. The idea that health in old age can be influenced by one's own actions is not a new idea, either. For centuries, a healthy diet, exercise and moderation have belonged to the "toolbox" of anti-ageing strategies (Katz 1996). However, the modern version of this line of thinking, which can be called activity discourse, advocates the idea that, as with health in general, ageing and health in old age can and should be influenced through one's own actions and lifestyle choices (Featherstone \& Hepworth 1995; Gilleard \& Higgs 2000; Hepworth 1995; Katz 1996, 2000). It has been argued that activity representations of ageing and old age have increased in contemporary culture, in the media and in public discourse (Featherstone \& Hepworth 1995; Gilleard \& Higgs 2000; Katz 2000; Lee et al. 2007; Rozanova 2006; Williams et al. 2007). The growth of activity 
representations does not mean that decline discourse has altogether disappeared. Instead, activity is offered as a remedy for all sorts of ills of old age.

At the individual level, remaining active is offered as a strategy to fight illnesses, maintain functional ability, minimise health problems, resolve loneliness and enhance individual well-being; and on the level of society as a strategy to prevent dependency and to minimise the costs of health and social care provision for the ageing population (Hepworth 1995; Katz 2000). Even though activity discourse promises a more positive view of old age, it also constructs ageing as a matter of individual responsibility, and thus ageing has also become a matter of moral evaluation (Hepworth 1995). The responsibility and the ability to influence one's own health even in old age have become part of the scientific discourse, talk in the media, and everyday conversations (Hepworth 1995; Katz 2000).

Cultural discourses are important in that they offer "vocabularies" with which individuals can think about their own ageing and construct their own identity as old people. However, cultural modalities (discourses), dominant codes, values or categories should not be understood in a unitary fashion, or as forces that dictate our concepts of health: as well as being internalised, these discourses are also resisted and transformed, and their meanings ruptured (Crawford 1984). In this research cultural discourses are seen as resources that may enable but also limit people's own thinking. Less attention has been paid to how people use these discourses in their own thinking, apply them to their own lives and own ageing, or on what basis people adopt or discharge certain views.

In this study, I have analysed group discussions in which Finnish people aged 70 or over talk about their health. My aims were, firstly, to analyse in detail how the participants discussed their ability to influence their own health and their responsibility for their own health; and secondly, in more general terms, to explore the role of old age in discussions of health. In doing this, I wanted to study how different views were developed in interaction between the participants and how these views were evinced, supported or refuted. Following the ideas of the discursive approach, my research therefore comprised both the content of different arguments and how they were used in talk. 
International Journal of Ageing and Later Life

\section{Data and Methods}

The data consist of four group discussions with six participants each, including myself in the capacity of moderator of these discussions. The research participants were recruited by convenience and purposeful sampling. First, I recruited participants to whom I had easy access (members of an art club that I attended) and asked them to recommend other suitable participants. On the basis of my experiences with the first group, I contacted the manager of a local service facility and with her help recruited more participants. The discussions were held in the city of Tampere in southern Finland in 2000. Lasting from 60 to 90 minutes, the discussions were audio-recorded with the consent of each participant and transcribed verbatim ( 130 pages). Altogether there were 20 participants (eleven women, nine men), and their age ranged from 71 to 86 years. Background information (age in years, education and occupation at the time of retirement, marital status, housing, health status) was collected after the discussions by self-report questionnaires. Group 1 had five male participants, all of whom attended the same art group, and the discussion was held at the place where that group used to meet. The participants for the other three groups were resident and non-resident clients of one of the service facilities run by the city of Tampere, and these groups met on the premises of these facilities. Group 2 consisted of two married couples and one single woman, all of whom belonged to the same literature circle. Group 3 consisted of five women, two of whom lived at the service centre. Group 4 consisted of two men and three women, all of whom lived at the service centre in question. Groups 1 and 2 represent pre-existing groups, but in groups 3 and 4, too, the participants knew one another at least by sight, some of them were friends. The groups were thus rather heterogenous, since one aim of the study was to trace different perspectives and variation in experiences. All discussants took part voluntarily.

To initiate the discussions, I introduced myself and described the research project. I said I was interested in the participants' own views about health in general and their own health in particular, and also in what health means to them in their everyday lives. The discussions then proceeded according to a set agenda, although largely on each group's own terms. This procedure provided a common basis for the discussions, but allowed different views to emerge within and between the groups. 
Discussing Responsibility and Ways of Influencing Health

The discussions focused on the following topics:

- definitions of health, personal and general;

- the individual's own responsibility for health;

- to what extent can health be influenced by individual action;

- the most important things in one's own health, and possible future concerns about one's own health; and

- the relationship between age and health.

These topics were covered in all groups, although the weight they received differed from group to group. The exact wordings of the questions varied slightly between the different groups, because I adjusted the questions to best suit the interaction and the atmosphere in each group. Age was on the list of topics, but the participants brought up age and old age even without prompting. As a result, the discussions in each group were framed by ageing and old age. In the flow of their discussions, the participants also introduced and developed new topics. The transcribed text was loaded into Atlas.ti 5, a qualitative data analysis programme. The programme was used as a tool for organising and coding the data. The speech was transcribed word by word (see Appendix 1 for transcription conventions).

The study draws on the ideas of social constructionism (Gubrium \& Holstein 2008; Gubrium et al. 1994), emphasising "the dynamic contours of reality and the processes by which social reality is put together and assigned meaning" (Gubrium \& Holstein 2008: 3) and of discursive psychology (Potter 1996; Wetherell \& Potter 1992), pointing out the importance of language as a means of constructing versions of reality, oneself and others. The discourse analysis perspective offers tools for exploring the different, sometimes conflicting meanings attached to health and old age, and how these meanings are brought forward, substantiated or refuted (Potter 1996; Wetherell \& Potter 1992). More specifically, my approach combines ideas from situated and action-oriented discursive constructionism (Potter \& Hepburn 2008) with Foucauldian-influenced discourse analysis (Wetherell \& Edley 1999). In short, the view adopted here is that people's talk is about the local pragmatics of a particular conversational context, but also part of broader or more global patterns of collective sense-making (Wetherell \& Edley 1999: 338). My approach to the data and my own role within that data was guided by the idea of "active 
International Journal of Ageing and Later Life

interviewing" (Holstein \& Gubrium 1995). Active interviewing starts out from the idea that the researcher is never an impartial or neutral person, but the research data are produced jointly, in a collective exercise of meaning-making. My own role was a dual one. On the one hand, I was a moderator whose job it was to make sure that all participants got a say. On the other hand, I was an active participant in the discussions, encouraging and even provoking discussion. In this study, the notion of active interviewing was combined with focus groups as the method of data collection. The reason I chose to collect my data in the form of group discussions was that they offer an effective way of exploring the formation of shared beliefs and values and people's experiences, opinions, wishes and concerns (Barbour \& Kitzinger 1999; Waterton \& Wynne 1999). As Barbour and Kitzinger (1999) point out, the main idea of group discussions or focus groups is to address the group as a whole instead of asking questions of each person in turn and to make explicit use of group interaction to generate data. In this sense they differ from simple group interviews (Barbour \& Kitzinger 1999: 4-5). The advantage of focus groups in comparison to some other data collection methods is that focus groups also constitute a contextual method. The participants are not approached as individuals acting in isolation from the social context, but as members of a social group interacting with each other. The social context of group discussion provides an opportunity to examine the process of meaningmaking and how different views are formed, expressed, modified and debated with others (Wilkinson 1999: 67; see also Myers \& Macnaghten 1999). In addition, focus groups have a potential to be a non-hierarchical method since the group situation reduces the researcher's influence and leads into a greater emphasis on participants' views (Wilkinson 1999: 70), allowing participants to generate their own questions, frames and concepts and to pursue their own priorities in their own terms (Barbour \& Kitzinger 1999: 5). A special challenge in the context of group discussions is how to analyse interaction and talk of the group as a whole and the individual voices within the group (Barbour \& Kitzinger 1999).

The questions concerning responsibility and the possibilities of influencing one's own health offered a morally loaded perspective for discussion. One key concern in the analysis was to see whether the participants accepted the interpretation I evinced, or whether they challenged it and 
proposed other interpretations. Conventionally, morality refers to shared notions of good and bad, or right and wrong, which can be used to define both people and their behaviour. In philosophical discussions morality is also related to questions of individual agency and the nature and possibility of free will. These questions go beyond the scope of this article. However, the group discussion data and the discursive perspective adopted here present a useful opportunity to look at "morality-in-use" (Jayyusi 1991; Nikander 2002), which here means analysing the participants' talk in detail to see whether they construct the issue at hand as moral.

The findings of this study are based on an analysis of the whole dataset. The extracts presented were chosen to illustrate the commonalities and variation of meanings in talk, and on the other hand to show how the participants developed their views and joined or challenged others' views. Identifying names have been replaced with fictional names and $\mathrm{R}$ refers to researcher.

\section{Is Health Fate or One's Own Doing?}

The first extract comes from Group 2, which consisted of two couples (husband Henrik and wife Liisa, husband Taisto and wife Rauha) and one single woman (Sofia). Before the discussion reproduced below, I asked the participants to define health in general. The emphasis in these definitions (in all groups) was very much on the functional aspect of health, i.e. being able to cope in everyday life. Sofia then began to talk about her own health: "well for the time being I've managed, I think I've managed really well (laughs), but then I don't know what's coming". After asking the other participants how they assessed their own health, Henrik replied "good for my age", and Taisto "satisfactory for my age". Henrik explained his good health by saying that he had no "internal diseases", only "the odd flu and things like that" and "wear and tear". Taisto's "satisfactory" health status was explained (by his wife) by his cancer, for which he was still receiving treatment. His wife Rauha then went on to say "for her own part" that she had no ailments, no medication and that she had good mobility, but added that "you never know what's around the corner". 
International Journal of Ageing and Later Life

In summary, health was here defined broadly in terms of being able to function and having no real diseases, but only minor aches and pains. In this health context, old age was constructed as a time of deteriorating health, as was visible in the expressions "good for my age" and "satisfactory for my age". In the other groups this kind of talk was also common, and in earlier studies, too, "good for one's age" talk has emerged as a common discursive strategy that explains good health in old age but does not question the conventional view of old age as decline (Coupland \& Coupland 1994; Coupland \& Coupland 1999; Coupland et al, 1989; Jolanki et al. 2000). Sofia's and Rauha's remarks "I don't know what's coming" and "you never know what's around the corner" can be interpreted as being related to ageing, but also to illnesses in general. In this kind of talk health was constructed as a precarious state, and its

\section{Extract 1. Group 2}

R: $\quad$...Can you, is there something you can do yourself if you think that with increasing age you get all sorts of ailments, is there any way you can influence ( ) your own health then?

Henrik: at least your mental health (R: $\mathrm{mm}$ ) you can't do much about your physical health. They come and go (R: yes).

Liisa: well I suppose you can actually to some extent I mean I was just thinking that it would be nice to put my foot up on here, but heaven above if I accidentally put this foot up (laughs) then I will, I have to take my other foot out (laughs). I mean you have to remember what your weak points are (R: yeah). (murmurs of approval)

Henrik: and then I also thought that you can of course help yourself if you think that they easily say that there's no point going to see a doctor with a minor complaint like this and (R: $\mathrm{mm}$ ) but if you go to the doctor even if it's just something minor (R: yeah) to see a professional, you may well get help with things that you don't understand (R: right).

Liisa: and then there's like physical exercise. I mean if you've got healthy limbs and you try to exercise, I'm sure that that will help. Helps your muscles stay fit (R: yeah) but then this is definitely a factor ( ${ }^{*}$ unclear $\left.^{*}\right)$ (R: right) you can't just, if 
Discussing Responsibility and Ways of Influencing Health

\footnotetext{
I think of myself, like in the wintertime when it was so slippery and I wasn't allowed to move around, now I feel that (laughs) I can't get out and about any more. But in the spring when I got out on my walks again, I mean everything was all back on track again () in a completely different way (R: right) so I mean you do begin to deteriorate pretty soon when you're older, not when you're younger, but when you're older (murmurs of approval), if you don't get any exercise that at least I,/I personally/

Sofia: /I/ know lots of people who when they've started to have these problems with their aches and pains and what have you, they've just slumped down in their armchairs, "oh dear the pain in my arms, oh dear or dear oh dear". Sometimes I say, "I say listen, try to lift your arm a bit, you know it could help. I can't move it at all, I can't move it at all." You really won't get anywhere (R: $\mathrm{mm})$, I mean if you start going down this road, I mean with each and every complaint you say that I can't get anywhere (R: yes). One day you will no doubt get to the point that you really can't move, but that's sometime in the future.
}

alterations seemed to be beyond the individual's control. Next, I moved on to ask how the participants saw their chances of influencing their own health.

In this extract health was jointly constructed as something that can be influenced, but different explanations were evinced for the origins of good health as well as for the role of individual action. Firstly, Henrik's talk constructed mental and physical health as distinct areas, and the latter as something beyond the individual's control. However, I have interpreted his reference to "they come and go" (line 5) to mean diseases rather than health in general. In her response Liisa contrasted with Henrik's view, but her talk implied a more general view of health, that is, health as functional ability. Disagreeing with the former speaker, as she did, is often a delicate matter. She delayed her comment (line 6 "well I suppose") and toned it down in advance ("to some extent"), which in itself suggests that her talk will take a critical stance on what was said earlier. "Influencing" was also given a different interpretation in which it was related to individual differences and to the need to adjust oneself to one's limitations ("weak points"), which helps to avoid health problems. "Weak points" refers to inherited qualities, which in Liisa's talk serve as a self-evident cause constraining individual action. 
International Journal of Ageing and Later Life

After his wife's turn, Henrik also modified his view (lines 11-15) and suggested that one could try to enhance one's health by seeking medical advice, but received no support from the others. This topic was initiated by him on several occasions, but received little support. In his talk, Henrik implicitly contrasted ordinary people and their limited understanding ("you don't understand") with "professional people", " who know better". His talk diminished the role of individuals as agents, and this social position was not perhaps one that the others were prepared to support. Liisa's talk, on the other hand, emphasising the importance of individual actions, received more support, and was followed by similar talk by other participants. In these discussion groups the view that seeking medical help might have beneficial effects was quite rare, and was only mentioned in the context of "serious" diseases (such as cancer) and their treatment.

Liisa continued the theme of physical exercise, which was then supported by the others and remained one pervading issue in the discussion. Liisa's first turn (lines 16-25) in which she advocated the beneficial effects of exercise, implicitly again mitigated her husband's view that there is nothing one can do to influence one's physical health. The laughter and the point she made that she was only talking about herself ("if I think of myself", and "at least I, I personally" lines 19, 25), can be seen as a way of mitigating the implied criticism. Her talk could be heard not only as a criticism of her husband, but also as veiled criticism of other people who did not try hard enough to exercise. It is a delicate matter to accuse and blame others because that may be seen as a violation of the rules of interaction and the speaker may him/herself be blamed for praising him/herself and for being too judgemental about others. Liisa's emphasis on the personal aspect can therefore be interpreted as a move to try and avoid these interactional hazards.

On lines 22-23, her factual statement "so I mean you do begin to deteriorate..." marked Liisa's talk as a closure to the earlier theme of old age. Both weather problems, inherited qualities ("weak points") and old age served here as external forces that were beyond individual influence. However, she modified this view by referring to the possibility of alleviating health problems and slowing down the ageing process by exercise (line 24). 
Sofia's turn (lines 26-33) continued the exercise theme. Her talk contrasts herself with unnamed others who are harming themselves, refusing or lacking the willpower to try and resist the health problems brought about by ageing ("when they've started to have these problems" lines 26-27). As a linguistic strategy, extreme case formulations ("I can't move it at all", "with each and every complaint") (Pomerantz 1986; Potter 1996: 87-188) and vivid quotations of others' talk (Drew 1998: 319 322; Potter 1996: 160-162) serve to demonstrate others' exaggerated reaction to their health complaints. Sofia's talk constructs these complaints as common, minor and somewhat vague ("their aches and pains", "each and every complaint" lines 27, 31-32) rather than as specific diseases. The expression "if you start going down this road" indicates that the unnamed others have (at least partly) chosen their lot, and also given in to indolence ("slumped down in their armchairs" lines 27-28).

Sofia's talk has a judgemental tone and as was previously stated, it is risky to judge others' behaviour. However, the linguistic strategies mentioned and the description of health complaints as minor ones serve to justify her disapproval of others' behaviour. Also, she qualified her judgemental tone by referring to future effects of old age (lines 32-33 "one day you will no doubt get to the point", "really can't move"), which in this context served to show that she was not being unreasonable. In summary, the participants' talk constructed serious diseases as a matter beyond individual control, but views about ageing and old age were more ambiguous. On the one hand, in this health context, old age was constructed as a process of inevitable deterioration accompanied by related health problems. On the other hand, individual decision-making and action was given an important role in enhancing one's own well-being and fighting the "effects" of old age in everyday life.

In Group 3 one of the participants talked about the literature circle in which she was involved and in that context raised the role of mental alertness in health (cognitive skills, social activity). I saw this as a chance to try and find out how the discussants would tackle question about mental aspects and their influence on health. My question was very loosely 
International Journal of Ageing and Later Life

\section{Extract 2. Group 3}

R: $\quad$ yes. What about then () one's own () attitude and these kinds of mental factors () how do they affect one's health? I was just thinking that if you take part in this literature circle and, you know that this.

Lea: well yes I certainly believe that this kind of mental side it, I'm sure.

Aira: keeps up your mental agility ().

Lea: yes and that it has a major influence on your health, at least you would think it has some effect between your ears.

(talks about the pieces she writes for different magazines)

(...)

Aira: so that you can make a difference by what you do.

Sylvia: yes.

Aira: to how you feel, to feeling good.

Lea: yes so that you don't just lie down/just/

Aira: /yes, that you don't just stay there/

Lea: right and don't get in/touch with anyone/

Aira: /yes that really is/, that gets you down.

Lea: depressed.

Aira: in no time at all.

Esteri: yes and when I get this depressed feeling and I know it will go away, I realise that and I notice it when it (laughs) starts to come (laughs), everything's pretty dark when it creeps up on you, but at that point / I'll start to do something/

Lea: /well I'm not/

at all surprised in your position.

Esteri: $\mathrm{mm}$

Lea: when you're always there at home.

Esteri: /yes right/

Lea: /born and bred/in the same place/and never go anywhere/

Esteri: /yes but it doesn't really, for me/it, it doesn't for me at all because I'm comfortable there.

Aira: /yes you/

Esteri: /I'm comfortable / I don't miss.

Lea: don't you get bored?

Esteri: no, you see I'm not really the *outgoing* type.

Lea: yes. 
formulated in order to give the participants the chance to address those dimensions that they considered most relevant.

In theory, the loosely formulated question might have received different interpretations, and the participants could have interpreted my reference to "mental factors" as meaning something other than the individual's own outlook and attitude. One might imagine that belonging to a literature circle would produce all sorts of pleasant experiences that enhance wellbeing. Instead, mental activities receive a rather instrumental meaning here as a means of improving one's mental agility.

At first, Lea took to this issue very eagerly, and began to talk before I had time to finish my questions. She voiced the view that her writing had helped her retain her cognitive skills (lines 4, 6-7). Lea and Aira together constructed the view that mental activities and the preservation of mental agility have an effect on health, and secondly that mental well-being ("feeling good") and mental agility are a result of one's own outlook and decision to be active. In this way, elements of everyday existence were converted into activities (Katz 2000: 140-141) that promote health in old age. Lea's and Aira's talk is rhetorically very effective, creating a vivid image of the unfortunate stagnation into which people may fall if they fail to lead an active lifestyle. Clearly, this kind of metaphorical expressions (lines 13-14 "don't just lie down", "don't just stay there") were "doing far more than designating physical positions", as Williams has stated (1993: 104). Lea's and Aira's talk carries the implicit message that mental 
International Journal of Ageing and Later Life

problems may be induced or avoided by one's own actions, and people can choose how to behave, i.e. whether to "just lie down" or be socially active. The view that social and physical activity and being "positive" somehow generates health was very common in these discussions. Similar findings have been made in earlier research as well. Crossley (2002) found that discussants in her focus group data linked good health with being extrovert, taking exercise and having a positive mental attitude to life (ibid: 1471).

Esteri joined the conversation (line 19) and began talking about her own depressive mood. Apparently, she was trying to show that she agreed with the former speakers by saying, "yes and when I get", and explaining then, "but at that point I'll start to do something" (lines 19-21). However, she was interrupted by Lea, who burst into the talk which constructed Esteri's sentiments as a natural and inevitable consequence of her own actions, namely staying indoors and avoiding social contact. The extreme formulations in Lea's talk ("not at all surprised", "always there at home", "never go anywhere") underline the idea that Esteri is one of those people who has chosen to be socially inactive, and her conduct was in fact constructed as a lifetime habit (line 27 "born and bred in the same place..."). Lea's interruption could be seen as offending, but it was not received as such by Esteri, who defended herself very calmly. Here, as in the earlier extracts, the fact that the participants knew one another, and the friendly atmosphere in the group, apparently made it possible for strong disagreements to be voiced and resolved.

Yet Esteri's response was defensive, which indicates that she interpreted Lea's talk as condemnatory. Her response was to define herself as someone who does not need social contacts to the same extent as a more "outgoing type" (line 33) might. Her talk introduced the idea that people are different, and what is good for one person is not necessarily so for another. In this way she rebutted any doubts that her situation might have been caused by her social inactivity. At a more abstract level, this whole episode can be heard as everyday theorising about what counts as activity, and whether social activity which is largely accepted as an important element in promoting older people's health can be taken as the standard applicable to all people (Katz 2000: 143). Furthermore, in Esteri's talk depression appeared as an active agent which comes and goes with 
great predictability (line 36 "it always comes"), and all she could do was to try to adapt. But by pointing out that "I do then always find the help" (line 35) she also constructed herself as an agent, not only as a victim of disease. It is potentially face threatening to confess that one suffers from mental problems, and Esteri's laughter can be seen as one way of reducing the seriousness of her revelation. However, the extreme case formulations "everything's pretty dark" and "pretty strong" (lines 20-21, 36-37) do construct her symptoms as serious, which can be interpreted as an interactional move to prove that she was not complaining for nothing. Towards the end of the excerpt, Aira and Taimi joined the discussion. Aira's talk mitigated her earlier strong view and constructed depressive feelings as natural for all people ("that goes for everyone"), but still as result of being alone (line 43). Taimi then continued the weather theme introduced by Esteri (line 40 "sunny days") and offered bad weather as an obvious cause for feeling depressed. Consequently, in their talk depression and depressive feelings are equated with natural forces, and as changeable as the weather. Aira and Lea did not seem to abandon their view that individual action has an influence on health, but they did soften it. As the conversation unfolded, the group moved towards a more moderate view, that is, that health may be a matter of individual action, but the same rules do not apply to all people and some things are beyond individual control.

\section{Responsible or Not?}

Questions of responsibility were often followed by lengthy accounts of appropriate or inappropriate conduct. Another very common feature of these discussions was that the participants talked at one and the same time about their own health and health in general, as happened in the following extract.

Extract 3. Group 2

\footnotetext{
R: $\quad$ what about I mean () you must have you read () you watch television and there's a lot about () these health matters () you should look after your health in different ways I mean there's physical exercise, diet and things like this, what do you think, to what extent are people responsible for their own health?
} 
International Journal of Ageing and Later Life

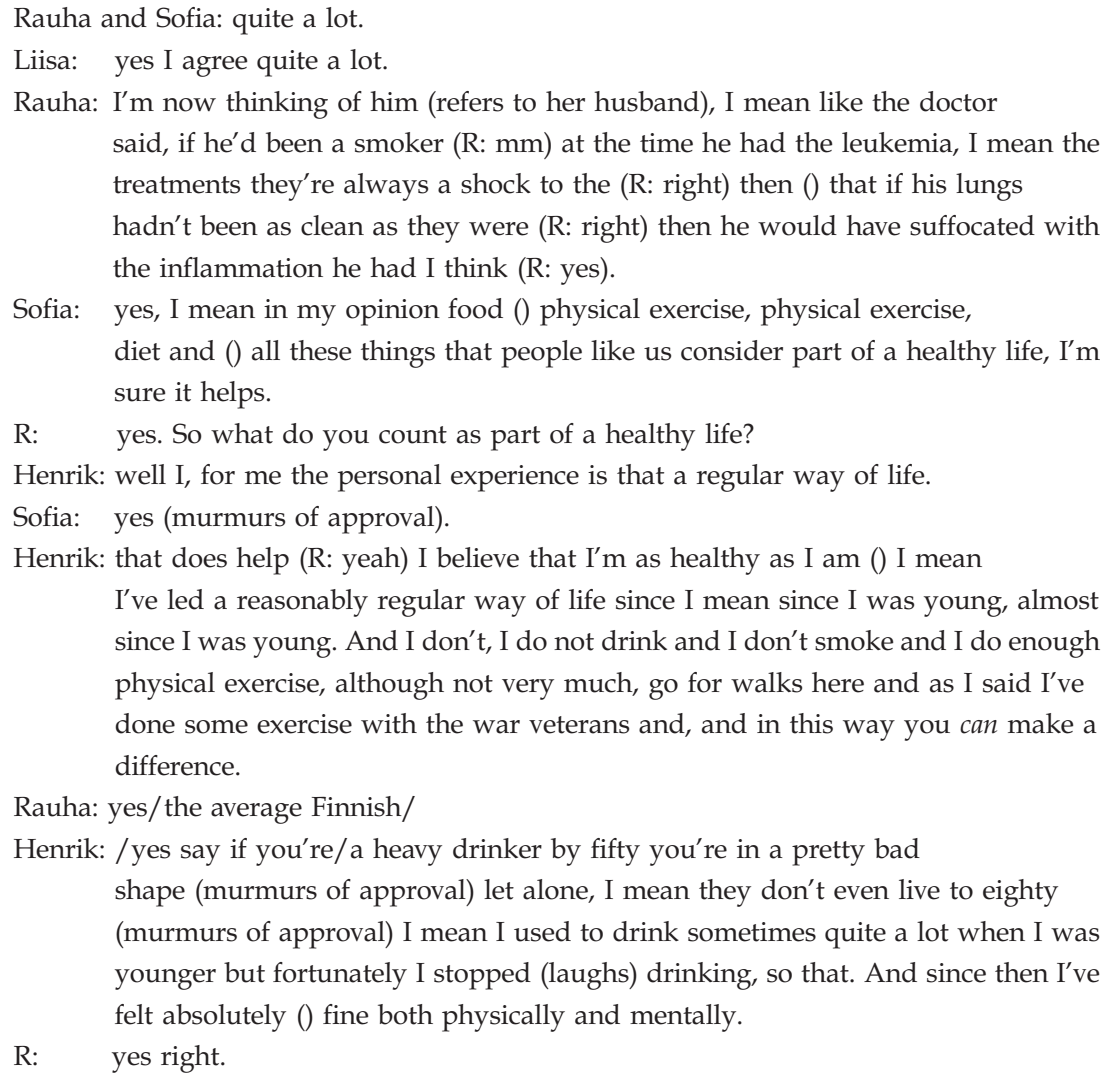

In the earlier extract from this same discussion, exercise was discussed at some length as a way of improving one's health (physical fitness). Here, my introduction offered exercise and diet as means of taking care of one's health, and connected them with individual responsibility. The introduction clearly stated that looking after one's health is the appropriate thing to do (line 2 "you should look after your health..."), but by embedding these demands in a wider social context I tried to keep the floor open to different views. The participants did not challenge the interpretation 
offered, but they did qualify it during the discussion. At first, in response to my question, Sofia and Rauha replied in the affirmative, laying a heavy burden of responsibility on the individual's shoulders (lines 5-6 "quite a $\left.l^{\prime \prime}{ }^{\prime \prime}\right)$. Rauha's example was quite extreme, quoting her husband's nonsmoking as the factor that saved his life. A doctor is called upon as an "outside witness", an authority whose words proved that what Rauha was saying was true. Later on, she moderated her rather extreme causal statement with the expression "I think" (line 11) that ends her turn. These extreme views about responsibility were also mitigated by Sofia and Henrik, who used the word "help" (lines 14,18) to describe people's own influence. In their talk then, people's own actions do make a difference, but they are not the causes of good or poor health.

The participants talk constructed a division between we ("people like us"), who lead a healthy life and other, unnamed people ("smokers", "boozers") whose lifestyle is healthy and even life-threatening. However, to talk about a "regular way of life" (line 16) and the "average Finnish" life (line 24) constructs a moderate lifestyle as preferable to extreme behaviour. The participants' talk here reiterates the findings of earlier research. This kind of talk can be called "a harmony" principle in health beliefs (Herzlich 1973). Backett (1992), too, said her respondents condemned excess in health-seeking behaviour and actually denounced it as unhealthy (ibid: 261-264). In this respect, Henrik's turn (16, 18-23, 25-29) is interesting in many ways. He introduced the idea of "a regular way of life" and pointed out that he did not overdo a healthy lifestyle, but took "enough physical exercise". He balances between confessing that he does not go very often for walks, but still takes enough exercise. In this way he shows that while he does assume responsibility for his health, he does not overdo things. In this extract then, as I see it, the participants constructed a morally grounded division between different factors that influence the individual's health, of which smoking and alcohol use are considered the most reprehensible. This division was constructed in other groups as well.

Henrik's confession of his earlier, sometimes heavy alcohol consumption (lines 27-28) is particularly interesting in this context. Earlier, he had made it clear that he is aware of what a healthy lifestyle implies (lines 16-23 and extract 1 ) and that he tried to lead his life accordingly. I construed that in this context, his admission did not threaten his image as a "pro-health 
International Journal of Ageing and Later Life

person". Also, it is more acceptable for a man than for a woman to admit to excessive drinking, especially if this is something that happened in one's youth (cf. Backett 1992: 260). The mention of personal experience softened the moralising tone, and strengthened Henrik's claim in two ways: it showed that he was not trying to set himself above the others; and also that he had first-hand knowledge of what he was talking about, lending added credence to his words (Potter 1996: 112-113).

Not all the participants claimed that they tried to lead a healthy life, understood as taking exercise and having a healthy diet. However, anyone who admitted to leading a not-so-healthy life always expressed the view that one should try to look after one's health. The following extract sheds light on this kind of talk. In Group 1, the discussion had revolved very much around social issues, and I framed my question of responsibility accordingly.

My question suggested that there is a contrast between the individual and the society, and offered social development and public expenditure as a

Extract 4. Group 1

R: yes() so what about could you think then that () I mean there's been a lot of talk in the media now that with money running out and with these questions of priorities that() what costs should be covered and what society should pay for () is it fair to say that people are responsible for their own health I mean to what extent are people responsible for being for () I mean if we talk not only about being able to influence one's health but are people responsible for their health and what is society's role in all this?

Paavo: yes well if you mean that do I feel guilty for not going out for walks then yes (muted laughter).

R: $\quad$ yes, I mean for not going out, is that what you're saying?

Paavo: yes because I don't go out.

R: $\quad$ right.

(.)

Paavo: yes it's true, I mean you do feel that you could do more for your own health, you could do more. 
Discussing Responsibility and Ways of Influencing Health

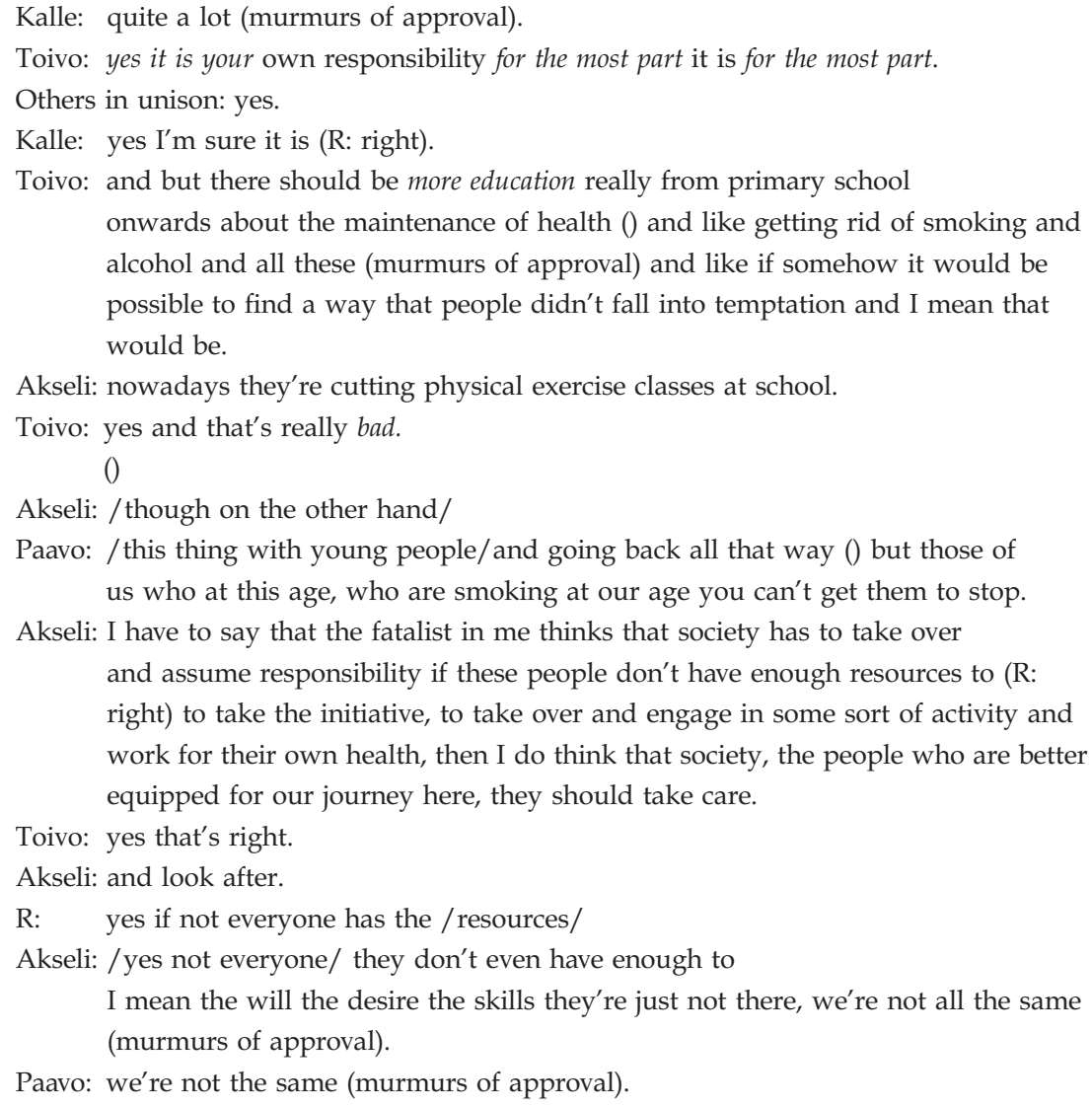

frame for discussing the question of personal responsibility. As the discussion shows, society was accepted as a key notion and vantage point for the discussants' definitions of responsibility, but different meanings of responsibility still emerged in the discussion.

Paavo answered (lines 8,11) my question with a personal confession of not going out for walks. It is interesting that he formulated his answer to my question as a counter question, "translating" mine to contain an 
International Journal of Ageing and Later Life

explicit moral message of good individual behaviour. His concluding comment that one should and could do more for one's own health met with the approval of the others (line 16). With this talk, the participants constructed themselves as people who understand the value of looking after one's own health in spite of admitting to not doing enough. The discussion that follows (lines 17-19) confirms that they accept personal responsibility for their health. This is evident in Toivo's heavily stressed talk and repeated expression "for the most part" (line 17), which is joined by others and Paavo's closure "yes I'm sure it is". In spite their assertiveness Toivo's words ("for the most part") leave some room for factors other than personal responsibility. These other factors were addressed when he raised the perspective that changed the course of the discussion altogether. Toivo's talk about the need for "education" (lines 20-24) reduced the demand for individual responsibility in that it constructed a healthy lifestyle as a matter of knowledge and appropriate education. Physical exercise and the avoidance of alcohol and tobacco were raised as self-evident issues in a healthy way of life, as in other groups.

Toivo's expression "to find a way that people didn't fall into temptation" and Akseli's remark about "they" who are cutting exercise classes at school implicitly constructed two kinds of actors in health, i.e. authorities and ordinary people. In the participant's talk ordinary people's responsibility and chances to look after their own health were dependent on the actions of some unnamed authorities. However, it is clear from the comments about school education, and from Paavo's comment on the futility of trying to change one's habits in old age, that the participants were talking about the health of young people. The participants' own talk seemed to implicitly confirm the view that "old dogs don't learn new tricks"; attempts at lifestyle changes are best left to young people.

Akseli's turn (lines 29, 31-35, 37) shifted the emphasis to talk about people in general. His talk constructed a distinction between people who do not have the means or the resources to look after their health, and those who do ("people who are better equipped"). Differences in health were constructed as a matter of education, different resources and inherent qualities, which was confirmed later on (lines 40-42) in unison: "we're not all the same". Initially, the responsibility was mainly laid on the 
individual's shoulders, but this view was qualified in Toivo's turn; and eventually Akseli's turn and the subsequent talk shifted much of the responsibility to society and to those individuals who were better "equipped" than others. In this extract I asked the participants to express their views on society's and individual's responsibilities. However, collective responsibility for people's health was raised in other groups too without prompting, even though the discussions of responsibility revolved mainly on individual responsibility.

\section{Discussion}

In this study the aim was to find out how the participants would respond to questions about the possibilities of individuals to influence their own health and their responsibility for health, what would be the role of old age in this context, and how these topics would be discussed in a group situation. Some participants agreed more strongly than others with the idea that people can influence their health and that they can and should bear individual responsibility for their health, while other participants offered more moderate views. However, during the discussions both oriented to each others' talk, and qualified and developed their views jointly.

It has been suggested that group pressure in group discussions tends to steer talk towards unified "public" views and to inhibit the voicing of sensitive issues or individual disagreement. My experiences do not fully support this view since in these discussions, disagreements were indeed expressed and delicate personal issues raised. The findings presented here concur with Kitzinger and Farquhar (1999) views that the composition of the group, the topic and the overall sentiments of the group and the role of the moderator play a decisive role in enabling or prohibiting discussion on sensitive issues. I conclude that the atmosphere of the discussions had a major role in enabling or impeding multidimensional talk, and this is something the researcher (or interviewer or moderator) can influence. In the present data the participants in each group knew one another at least to some extent, which may be one crucial factor (Barbour \& Kitzinger 1999: $8-9)$. Instead of group pressure, I would be inclined to talk about interactional courtesy rules that people follow in order not to offend other discussants, and yet manage to express opposing views by subtle verbal and non-verbal means. 
International Journal of Ageing and Later Life

Even though the health talk in this data was ambivalent, it was clear from the analysis that the participants in these group discussions did not question the individuals' ability to influence their own health, or their responsibility for their own health in principle. This finding could be attributed to asymmetrical power relations in interaction. By this I mean that the participants may have seen me, the researcher and the questions I asked, as representing the voice of authority and shared cultural norms. For example, the discussion in group 1 (18) about responsibility in which the participants expressed their sense of guilt for not doing enough for their health, indicates that this is how the participants saw the situation. However, in reporting her experiences of data collection, Backett (1992) has argued that in spite of her attempts to be non-judgemental, the majority of the respondents "felt the need to apologise for and justify aspects of their life which they thought might seem unhealthy" (ibid: 261). This indicates that the subject of health may engender moral talk, irrespective of the conduct of the interviewer. These findings are only logical, given that health is one of the central values in Western societies today and, that people define themselves and others at least in part by their "healthy" or "unhealthy" behaviour (Crawford 2006: 402). Dissenting voices do not easily surface in a research situation where respondents would have to challenge shared beliefs or values (Billig 1996 [1987]), but as the data showed, qualifying and contrasting views may be voiced. Apparently, the questions (even as strongly formulated as mine) directed but did not determine the content and course of the discussion, and did not prevent the participants from expressing opposing views in the end.

Group discussions indeed offered a site where different and contrasting and even conflicting voices could be expressed. The findings here support the idea that focus groups can work as a non-hierarchical method to reduce the researcher's influence and to gain insight into participants' conceptual worlds (Wilkinson 1999: 70). The findings also suggest focus groups can be used to study how people discuss morally laden and potentially sensitive issues of healthy lifestyles and responsibility for one's own health, and also as a site for the participants to "confess" and elaborate on what would conventionally be seen as unhealthy lifestyles or inactivity, both of which go against contemporary ideas of "healthism" 
and beneficiary effects of activity evident in public discussion and policy programmes. As Kitzinger and Farquhar (1999) argue, studying sensitive moments and topics in and with focus groups would help to "map out the boundaries and transitions between public/private, acceptable/unacceptable and routine/non-routine discourses among diverse groups in different situations" (ibid: 171). On the basis of this and other research (Cunningham-Burley et al. 1999; Waterton \& Wynne 1999), I would suggest that focus groups could be even used to inform theorising and policy-making, and to involve lay people into public debates and policy discussions. Also, focus groups and detailed analysis of talk and interaction could be employed to illuminate and deepen the findings of quantitative research, e.g. to construct questionnaires and to develop understanding of key issues or in a latter phase of research to "tease out the reasons for surprising or anomalous findings" (Barbour \& Kitzinger 1999: 6).

However, the challenge of focus groups is that they can end up bringing forward the voices of the most articulate and dominating participants, or suppressing contrasting and conflicting voices. The moderator's interactional skills are therefore crucial in enabling everyone to have a say without curtailing or forcing the discussion. Also, there may be various barriers to the participants' willingness or ability to acquire information and engage in discussion about health issues in general or their personal issues. Lay views therefore cannot simply be used to replace professional or scientific expertise or focus group data cannot be said to unproblematically represent the views of the whole community (Cunningham-Burley et al. 1999; Waterton \& Wynne 1999). The analysis still represents the analyst's interpretation of the discussions, and it is up to researcher to theoretically argue for the transferability of the findings. Focus groups also easily generate large amounts of data, which presents a challenge for the analysis. During the last years qualitative software programmes, such as Atlas.ti used in this study, have entered the field and greatly facilitate organising large volumes of data and for example checking both prominence and rareness of different topics and the broader context of data extracts, thus improving the rigour of the analysis. The challenge of catching the group effect while analysing individual voices within 
International Journal of Ageing and Later Life

discussions requires special attention but detailed methods of text analysis such as discourse analysis help to meet this challenge.

On the basis of the findings here it was evident that both activity and decline discourses with their moral implications were part of the participants' thinking. The participants often explained and justified their conduct in response to questions, or they evinced reasons for other people's behaviour. However, these accounts about personal experiences brought abstract discourses of health and old age to the level of everyday life and everyday decision-making. To summarise the content of the discussions in regard to the ideas of influencing and assuming responsibility for health, the participants' talk can be seen as a balancing act between two lines of argument; namely health as "do-it-yourself" versus health as a fate or chance. These situated and contrasting arguments themselves embody and draw on broader controversial health and old age discourses and reflect the ambiguous expectations of older people in contemporary societies.

The participants argued that it is possible to influence one's health, which in this context means taking steps to enhance one's well-being or even to prevent illness by means of certain lifestyle choices, that is physical exercise, non-drinking, non-smoking and a healthy diet, actively maintaining social relations, being involved in all sorts of activities, and taking a positive attitude to adversities. Within this line of argument, messages from epidemiological research of "risky" behaviour intertwine with recent messages from gerontological studies on the beneficiary effect of "positive" thinking and active lifestyle on health in old age (Gilleard \& Higgs 2000; Katz 1996). The participants in this study gave accounts of their own attempts to live a healthy life, but also expressed self-judgments of not doing enough for their health. As the findings showed, judgments could also be directed towards other people. Judgment of others and selfblame reflect the general moralisation of health (Crawford 1984: 70), a phenomenon that has been documented repeatedly in earlier studies. The pursuit of health has become not only a moral obligation and a sign of virtuous citizenship but a means to control and discipline individual lives. The findings here and elsewhere indicate that "healthism" is part of the older people's own thinking even if contrasting discourses persist too. 
"Healthism" (Crawford 1984) can be seen as a cultural discourse that partly overlaps and strengthens the messages of epidemiological and recent gerontological discourses on old age. Thus, if health is one of the "key words" in contemporary western cultures, "activity" is the key word in discussions of old age, describing much of today's public and policy discourses (Katz 2000). As a result, individualistic and activist discourses with their moralistic repercussions - that emphasize individual choices and activity as solution to the ills of old age are gaining recognition in the thinking of ordinary people themselves. In the talk of these participants, activity was constructed as a strategy with which it is possible to alleviate age-related health complaints, and sometimes binary oppositions were constructed between active and passive people. Metaphoric expressions such as "just lie down", "just stay there" or "slump down in their armchairs", were used to describe the unfortunate state of those people who chose not to fight adversity, but remained inactive and as a result harmed themselves. Even though the activity discourse can be seen as an empowering discourse that allows older people themselves to question ageistic views of their abilities and competency (Jolanki et al. 2000), it does problematise older bodies and lives as dependency prone and "at risk" (Katz 2000: 147). Activity discourse is also essentially individualistic, putting individuals under pressure to lead active self-caring lives (Jolanki 2004), which was visible in this data. The participants put forward the idea that it was possible to influence health in old age in a similar way as health in general. The idea that not only physical but social activities and a positive outlook on life may enhance one's own well-being and even improve health is not new (Herzlich 1973; Williams 1993). More recent and more directly age-related idea is that social participation and different mental activities can assume instrumental meaning as "activities" that can improve cognitive functioning and even postpone or prevent dementia (Gilleard \& Higgs 2000; Katz 1996). This theme is currently prominent in the media and various selfhelp books, and the findings here suggest that older people are now picking up on these ideas. The problem here is obviously not the maintenance of good health, but the tendency to reduce older people's social positions and lives into a health concern, which means that different aspects of older people's everyday lives are seen more and more as part of instrumental techniques to manage health (Katz 1996: 127; Katz 2000: 140-141). 
International Journal of Ageing and Later Life

However, the participants also qualified the role of individual action and raised factors that in their mind limit people's chances or even prevent them from influencing their own health, and in this way also detract from individual responsibility. Within fate discourse individual health was constructed as a matter of chance or fate and old age was constructed as a period of inevitable health problems which limit the individual's influence and for which the individual cannot therefore be held responsible. So, the discourse of decline or fate was also present in the participant's talk and it was used to qualify the expectations and demands inherent in activity discourse. Invoking good health in old age as more unlikely than ill-health ("good for my age") and describing poor health as inevitable in the future served to explain and justify the participants' health complaints. Serious diseases were identified as one of the factors that limit the individual's possibilities to influence their health. Diseases were constructed as external forces that "come and go" more or less unpredictably, and therefore they are beyond individual control. Different individual qualities and social resources were also constructed as factors that can either improve or undermine the individual's possibilities and abilities to look after their own health. The participants evoked the idea that people "are not the same" or do not have the same resources. This version of the fate discourse draws from and reproduces spiritual and philosophical considerations of human beings at the mercy of destiny (or god in religious discourses). Yet, perhaps paradoxically another underlying stream within the fate discourse comes from the messages of modern epidemiological research. While arguing for various actions the individual can take to improve his or her own health, epidemiological research also points out the areas beyond individual influence such as genetic propensities and probabilities.

Within fate discourse the task of society and more fortunate people was to level the differences and help out less fortunate people. So, even though discussions on responsibility for health revolved mainly around individual responsibility and individual actions, the participants qualified individual influence and also advocated the idea of collective responsibility for health as an alternative for individual responsibility. At the individual level then, the participants' talk touched upon similar issues of collective responsibility, the role of communities in people's lives and the division of obligations and rights which are becoming more and more crucial in 
wider debates about the course of development of modern welfare societies (Phillipson 2006: 206). In the participants' talk, the different factors served to legitimise one's own health complaints and evict the moralising view that people in ill-health have brought about their own situation.

Thinking of old age and health furnishes ambiguous elements whose origin lies in wider social and cultural discourses and developments of western, or to be exact, European-American societies. Scientific inquiry and growing gerontological and epidemiological knowledge has helped to question and challenge overly determinist views of health in old age and to argue for more positive views of old age as a matter that can be influenced with one's own choices and actions (Katz 1996). Research results then have served as a tool for empowerment and questioning ageist thinking and practices. Yet, scientific inquiry can be seen as part of an even broader development of modernity and "consumerist late modern environment" (Blaikie 2006: 15, see also Gilleard \& Higgs 2000: 170) within which individual choice and agency are advocated as a means of well-being and better health. Crawford (2006) sees "healthism" in somewhat similar terms as born out of tensions of consumer capitalism.

In addition, according to Blaikie, modernity's devaluation of older people as unproductive has been replaced by older people's potentially productive roles as "purchasers of goods signifying particular lifestyles", and the pursuit of health serves as a tool for positive ageing and for preserving youthfulness (Blaikie 2006: 15; see also Featherstone \& Hepworth 1995; Katz 2000). Advocating individual activity and choices and individual responsibility for one's own life and health has been further fuelled by alarmist views of population ageing and financial troubles allegedly awaiting advanced economies in response to the ageing of populations (Blaikie 2006: 13-14; Katz 1996: 128; Tulle 2004: 176). As part of the attempt to better manage ageing of populations, neoliberal goverment policies in different countries aim to strengthen the role of individuals as consumers making choices and seek to shift the responsibility for health and social care costs to individual consumers and their choices (Gilleard \& Higgs 2005: 57; Phillipson 2006: 203). These trends offer different interpretive possibilities and lifestyle choices for individuals. They can be seen to work to liberate people from overly deterministic thinking of 
International Journal of Ageing and Later Life

old age to pursue their individual goals and interests and empower older people to take their lives and well-being and health into their own hands. The other side of the coin is that "activist" and "healthist" discourses can work as emotional and symbolic "straitjackets" compelling people to direct their activities and interests to pursue active and healthy lifestyles in accordance with normative expectations. Furthermore, within these discourses inactivity and ill-health even in old age can be seen in individualistic terms as responsibility and failure of the individual (Featherstone 1991). In this respect, the decline or fate discourse with its appeal to collective human fate offers liberation from individual blame.

The findings here are based on a small-scale study whose participants represent a group of elderly Finns. In view of the size of the population they therefore represent a small group of people. Qualitative studies do not usually aim or claim to provide generalisable knowledge in the same sense as quantitative research; instead we can consider transferability of the findings beyond the study context and whether the findings of qualitative research can feed and give ideas for discussing contemporary development of societies. On the basis of the findings and the references quoted, similar health and old age discourses are in circulation in different societies and have become part of the older people's own thinking. In this regard, the findings here are transferable to a broader context and echo ambiguous cultural discourses of old age and expectations addressed to older people in contemporary western societies. Health programmes, the media and numerous self-help books circulate ideas from scientific inquiry to a wider audience. Yet, these scientific and cultural discourses do not determine people's thinking. In their mundane decision-making people draw from broader discourses, but also from biographical particulars and practices of everyday life. Studies of older people's own meaning-making activities can show whether cultural discourses became lived reality. In summary, the participants constructed health and even health in old age as matters that the individual "can do something about", and to a certain extent should act upon. In the end, however, old age, serious diseases, individual differences and social factors represented either the unpredictable or common fate of all people or belonged to realm of collective responsibility, and in any case challenged the belief that the autonomous 
individual has the capacity "to re-make self and world" (Crawford 2006: 403).

\section{Corresponding Author}

Outi Jolanki, Tampere School of Public Health, University of Tampere, Finland. Email: outi.jolanki@uta.fi

\section{References}

Backett, K. (1992). Taboos and excesses: Lay-health moralities in middleclass families. Sociology of Health and Illness 14(29): 255-279.

Barbour, J. \& Kitzinger, J. (1999). Developing Focus Group Research. Politics, Theory and Practice. London: Sage.

Billig, M. (1987/1996). Arguing and Thinking: A Rhetorical Approach to Social Psychology. Cambridge: Cambridge University Press.

Blaikie, A. (2006). Visions of later life: Golden cohort to generation Z. In J. A.Vincent, C. R. Phillipson \& M. Downs (eds.) The Futures of Old Age (pp. 12-19.) London: Sage.

Coupland, J. \& Coupland, N. (1994). "Old age doesn't come alone": Discursive representations of health-in-ageing in geriatric medicine. International Journal of Aging and Human Development 39(1): 81-95.

Coupland, N. \& Coupland, J. (1999). Ageing, ageism and anti-ageism. Moral stance in geriatric medical discourse. In H. E. Hamilton (ed.) Language and Communication in Old Age. Multidisciplinary Perspectives (pp. 177-208). New York and London: Garland Publishing Inc.

Coupland, N., Coupland, J. \& Giles, H. (1989). Telling age in later life: Identity and face implications. Text 9(2): 129-151.

Crawford, R. (1984). A cultural account of "health": Control, release and the social body. In J. B. McKinlay (ed.) Issues in the Political Economy of Health Care (pp. 60-103). New York and London: Tavistock Publishing.

Crawford, R. (2006). Health as meaningful social practice. Health 10(4): 401-420.

Crossley, M. (2002). Could you please pass one of those health leaflets along?': Exploring health, morality and resistance through focus groups. Social Science \& Medicine 55: 1471-1483. 
International Journal of Ageing and Later Life

Cunningham-Burley, S., Kerr, A. \& Pavis, S. (1999). Theorizing subjects and subject matter in focus group. In J. Barbour \& J. Kitzinger (eds.) Developing Focus Group Research. Politics, Theory and Practice (pp. 186199). London: Sage.

Drew, P. (1998). Complaints about transgressions and misconduct. Research on Language and Social Interaction 31(3\&4): 295-325.

Featherstone, M. (1991). The body in consumer culture. In M. Featherstone, M. Hepworth \& B. S. Turner (eds.) The Body: Social Process and Cultural Theory (pp. 157-196). London: Sage.

Featherstone, M. \& Hepworth, M. (1995). Images of positive aging: A case study of Retirement Choice magazine. In M. Featherstone \& A. Wernick (eds.) Images of Aging. Cultural Representations of Later Life (pp. 29-47). London and New York: Routledge.

Gilleard, C. \& Higgs, P. (2000). Cultures of Ageing: Self, Citizen and the Body. Harlow, UK: Prentice-Hall.

Gilleard, C. \& Higgs, P. (2005). Contexts of Ageing. Class, Cohort and Community. Cambridge: Polity Press.

Gubrium, J. F. \& Holstein, J. A. (2008). The constructionist mosaic. In J. A. Holstein \& J. F. Gubrium (eds.) Handbook of Constructionist Research (pp. 3-10). New York and London: Guilford Press.

Gubrium, J. F., Holstein, J. A. \& Buckholdt, D. R. (1994). Constructing the Life Course. New York: General Hall Inc.

Hepworth, M. (1995). Positive ageing. What is the message? In R. Bunton, S. Nettleton \& R. Burrows (eds.) The Sociology of Health Promotion. Critical Analyses of Consumption, Lifestyle and Risk (pp. 176-190). London and New York: Routledge.

Herzlich, C. (1973). Health and Illness. London: The Academic Press.

Holstein, J. A. \& Gubrium, J. F. (1995). The Active Interview. Thousands Oaks, CA: Sage.

Jayyusi, L. (1991). Value and moral judgement: Communicative praxis as moral order. In G. Button (ed.) Ethnomethodology and the Human Sciences (pp. 227-251). Cambridge: Cambridge University Press.

Jolanki, O., Jylhä, M. \& Hervonen, A. (2000). Old age as a choice and as a necessity: two interpretative repertoires. Journal of Aging Studies 14(4): 359-372. 
Jolanki, O. (2004). Moral argumentation in talk about health and old age. Health: An Interdisciplinary Journal for the Social Study of Health, Illness and Medicine 8(4): 483-503.

Katz, S. (1996). Disciplining Old Age. The Formation of Gerontological Knowledge. Charlottesville and London: University Press of Virginia.

Katz, S. (2000). Busy bodies: Activity, ageing and management of everyday life. Journal of Ageing Studies 14(2): 135-152.

Kitzinger, J. \& Farquhar, C. (1999). The analytical potential of 'sensitive moments' in focus group discussions. In J. Barbour \& J. Kitzinger (eds.) Developing Focus Group Research. Politics, Theory and Practice (pp. 156172). London: Sage.

Lee, M. M., Carpenter, B. \& Meyers, L. S. (2007). Representations of older adults in television advertisements. Journal of Aging Studies 21: 23-30.

Myers, G. \& Macnaghten, P. (1999). Can focus groups be analysed as talk? In J. Barbour \& J. Kitzinger (eds.) Developing Focus Group Research. Politics, Theory and Practice (pp. 173-185). London: Sage.

Nikander, P. (2002). Age in Action: Membership Work and Stage of Life Categories in Talk (p. 321). Helsinki, Finland: Academia Scientiarum Fennica.

Phillipson, C. (2006). Ageing and globalization. In J. A. Vincent, C. R. Phillipson \& M. Downs (eds.) The Futures of Old Age (pp. 201-207). London: Sage.

Pomerantz, A. (1986). Extreme case formulations: A way of legitimizing claims. Human Studies 9: 219-229.

Potter, J. (1996). Representing Reality. Discourse, Rhetoric and Social Construction. London: Sage.

Potter, J. \& Hepburn, A. (2008). Discursive constructionism. In J. A. Holstein \& J. F. Gubrium (eds.) Handbook of Constructionist Research (pp. 275-293). New York and London: Guilford Press.

Rozanova, J. (2006). Newspaper portrayals of health and illness among Canadian seniors: Who ages healthily and at what cost? International Journal of Ageing and Later Life 1(2): 111-139.

Tulle, E. (2004). Rethinking agency in later life. In E. Tulle (ed.) Old Age and Agency (pp. 175-189). New York: Nova Science Publishers. 
International Journal of Ageing and Later Life

Waterton, C. \& Wynne, B. (1999). Can focus groups access community views? In J. Barbour \& J. Kitzinger (eds.) Developing Focus Group Research. Politics, Theory and Practice (pp. 127-143). London: Sage.

Wetherell, M. \& Edley, N. (1999). Negotiating hegemonic masculinity: Imaginary positions and psycho-discursive practices. Feminism and Psychology 9: 335-356.

Wetherell, M. \& Potter, J. (1992). Mapping the Language of Racism. Discourse and the Legitimation of Exploitation. New York: Columbia University Press.

Wilkinson, S. (1999). How useful are focus groups in feminist research? In J. Barbour \& J. Kitzinger (eds.) Developing Focus Group Research. Politics, Theory and Practice (pp. 64-78). London: Sage.

Williams, A., Ylänne, V. \& Wadleigh, P. M. (2007). Selling the 'elixir of life': Images of the elderly in an Olivio advertising campaign. Journal of Aging Studies 21: 1-21.

Williams, G. (1993). Chronic illness and the pursuit of virtue in everyday life. In A. Radley (ed.) Worlds of Illness. Biographical and Cultural Perspectives on Health and Disease (pp. 92-107). London and New York: Routledge.

\section{Appendix 1: Transcription conventions}

- overlapping speech starts and ends: //

- particularly quiet speech: * *

- clear pause: ()

- comment, unclear speech or possible interpretation in brackets: (unclear)

- heavy stress underlined: weak 